\title{
El lenguaje soez como reflejo de la cultura: conceptualización y taxonomía para la traducción audiovisual al español
}

\author{
Vanessa Pérez Rodríguez / Cristina A. Huertas Abril / M. ${ }^{a}$ Elena Gómez Parra \\ Universidad de Córdoba \\ z62perov@uco.es, cristina.huertas@uco.es \& elena.gomez@uco.es \\ https://dx.doi.org.10.12795/futhark.2017.il2.06
}

Fecha de recepción: 21.06 .2017

Fecha de aceptación: 15.09.2017

Resumen: La traducción audiovisual entraña diversas dificultades propias de su campo como, por ejemplo, la adecuación a la duración del discurso o al movimiento labial del actor o actriz que aparece en pantalla. A esto se ha de añadir el papel de la cultura en los productos audiovisuales. Así, si hablamos de la adaptación cultural en traducción audiovisual, una de las mayores dificultades radica en la traducción y adaptación del lenguaje soez de la lengua origen a la lengua meta. Una misma expresión catalogada como ejemplo de lenguaje soez en la lengua original puede traducirse de diferente manera dependiendo del contexto situacional, social y cultural que atraviesa el personaje que la pronuncia en ese momento. Es por todo ello que parece casi imposible proponer un solo equivalente en lengua meta para cada caso en lengua origen. Partiendo de la complejidad de la adaptación del lenguaje soez en la traducción audiovisual, para este estudio se ha tenido en cuenta la propuesta de categorización del lenguaje soez u ofensivo de Wajnryb (2005) en lengua inglesa para el desarrollo de la conceptualización y taxonomía del lenguaje soez para la lengua española.

Palabras clave: traducción audiovisual, adaptación, lenguaje soez, taxonomía, categorías.

\section{Foul Language as a Reflection of Language: Conceptualization and Taxonomy for Audio-Visual Translation into Spanish}

Abstract: Audiovisual translation entails various difficulties specific to its field, such as the adaptation to the duration of the speech or the lip movement of the 
actor or actress on the screen. To this, the role of culture in audiovisual products must also be considered. In this light, regarding cultural adaptation in audiovisual translation, one of the greatest difficulties lies in the translation and adaptation of foul language from the source language to the target language. The same expression catalogued as an example of foul language in the original language can be translated differently depending on the situational, social and cultural context of the character who pronounces it at that moment. For all these reasons, it seems almost impossible to propose a single equivalent in the target language for each case in the source language. Starting from the complexity of the adaptation of the foul language in audiovisual translation, for this study we have taken into account the proposal of categorization of foul language developed in English by Wajnryb (2005) for the development of the conceptualization and taxonomy of foul language for the Spanish language.

Key words: audio-visual translation, adaptation, foul language, taxonomy, categories.

Sumario: I. El lenguaje soez y la traducción audiovisual. 2. Principales taxonomías del lenguaje soez. 3. Conceptualización y taxonomía del lenguaje soez para la lengua española. 3.I. Blasfemias. 3.2. Disfemismos. 3.3. Insultos. 3.4. Juramentos. 3.5. Lenguaje obsceno. 3.6. Maldiciones. 3.7. Obscenidades. 3.8. Palabra tabú. 3.9. Palabrotas. 3.10. Vituperios. Conclusiones.

\section{El lenguaje soez y la traducción audiovisual}

Durante los últimos cinco años, se han llevado a cabo diversos estudios sobre la traducción del lenguaje soez u ofensivo en la traducción audiovisual; sin embargo, son más los estudios que se han centrado en la subtitulación (ÁvilaCabrera, 2015; Alcorisa, 2017) que en el doblaje (Soler, 2014; Català, 2017). Esto puede deberse principalmente a que el doblaje presenta una mayor complejidad que la subtitulación (Chaume, 2004).

Tradicionalmente, el método más utilizado para adaptar el lenguaje soez u ofensivo era la neutralización o la omisión de estos términos (Scandura, 2004). En el caso de España, el consumo de productos audiovisuales extranjeros (y que, por lo tanto, necesitaban someterse a un proceso de traducción y adaptación) comenzó en una época marcada por una fuerte censura, algo que sucedía en menor medida en los países de origen, de modo que se reforzaba la omisión del lenguaje soez.

Sin embargo, es de especial importancia traducir y adaptar de manera correcta el lenguaje soez en los productos audiovisuales. Este tipo de lenguaje tiene una carga cultural, social y subjetiva muy importante que no debe perderse en el 
trasvase de la lengua origen a la lengua meta, ya que estaríamos perdiendo también gran parte del efecto y el significado que el original pretende. No obstante, esto no quiere decir que lo adecuado sea traducir literalmente el lenguaje soez u ofensivo, sino que deben tenerse en cuenta distintos aspectos fundamentales, entre los que destacamos las diferencias existentes entre el contexto sociocultural de la lengua origen y de la lengua meta, la intencionalidad del discurso del personaje en lengua origen y el efecto subjetivo que provoca en el público meta. Todo esto nos permitirá encontrar la fórmula más adecuada para traducir y adaptar estos términos.

\section{Principales taxonomías del lenguaje soez}

A fin de poder traducir y adaptar de manera adecuada el lenguaje soez en las obras audiovisuales, consideramos que un paso fundamental es intentar categorizar los diferentes casos que podemos encontrar.

Fuentes-Luque (20I4) propone una taxonomía basada en cinco categorías: sexo, escatología, religión, familia y nominalia. A pesar del interés de esta clasificación, consideramos que lo que para una cultura puede considerarse ofensivo o tabú, puede no serlo para otra; de igual modo, en algunos casos podría haber solapamientros entre las categorías (por ejemplo, "me cago en tu puta madre" incluiría tanto elementos escatológicos como familiares, e incluso sexuales si se considera "puta" como referencia a los actos sexuales).

Para nuestro estudio, nos resultan especialmente interesantes las categorías propuestas por Wajnryb (2005). Sin embargo, una traducción literal de la taxonomía de esta autora al español no se ajustaría al sistema cultural meta, en tanto que la lengua inglesa se muestra mucho más precisa al respecto (por ejemplo, al distinguir entre obscenity y profanity, o entre swear y oath, entre otras). En este sentido, es necesario destacar que Fuentes-Luque (20l4, p. 3) defiende que "cada país, cada comunidad, utiliza distintos patrones linguïsticos y marcos de referencia cultural para construir expresiones tabúes, las cuales conllevan intenciones pragmáticas y matices distintivos". Por todo ello, en el siguiente apartado se recoge una propuesta de conceptualización y taxonomía para la lengua española adaptada de la clasificación de Wajnryb (2005).

\section{Conceptualización y taxonomía del lenguaje soez para la lengua española}


Atendiendo a las diferencias culturales entre la lengua inglesa (lengua original) de la taxonomía de Wajnryb (2005), se ha identificado un total de diez categorías para la lengua española.

\section{I. Blasfemias}

De acuerdo con el Diccionario de la lengua española, una blasfemia es una "Palabra o expresión injuriosas contra alguien o algo sagrado" (RAE, 20I8). Por consiguiente, consistiría en utilizar palabras malsonantes mediante el uso de palabras contra cualquier cosa sagrada. Cabe destacar que lo importante es la intencionalidad de la expresión; así, "por Dios”, por ejemplo, es una locución común e incluso podría considerarse como convencional, de modo que no sería vista como una blasfemia a menos que tuviera la intención de ofender a un cristiano en particular.

\subsection{Disfemismos}

El Diccionario de la lengua española define los disfemismos como "Modo de decir que consiste en nombrar una realidad con una expresión peyorativa o con intención de rebajarla de categoría" (RAE, 2018). Se trata, por tanto, de la sustitución de un término neutro por otro deliberadamente ofensivo o despectivo, incluso con cierto toque humorístico o irónico, sin que necesariamente sea una palabrota o una palabra tabú. Ejemplos de disfemismos serían utilizar "estirar la pata" o "cascarla" en lugar de "morir" (aunque en este caso, en determinados contextos, el término "morir" podría considerarse una palabra tabú).

\subsection{Insultos}

En términos generales, en un contexto abusivo, cuando se emplean palabras malsonantes hacia alguien, la intención es insultarle. En términos más precisos, el insulto se reserva para usos abusivos con significado literal ("Eres un idiota, feo, gordo y lleno de granos"), en lugar de recurrir al sentido metafórico de la mayoría de las palabrotas ("Es un chulo de mierda"). En la práctica, las palabrotas y los insultos coexisten cómodamente ("Que te jodan, gilipollas de mierda"), combinando su poder abusivo normalmente con buenos resultados.

\subsection{Juramentos}

La palabra "juramento" tiene dos significados paralelos a los dos amplios contextos del uso del verbo "jurar". Uno de ellos es la promesa formal que se realiza al jurar poniendo por testigo a Dios o a la Biblia; en este caso el juramento 
sería el texto en sí que se recita en el acto de jurar y que tiene mucha más fuerza que la promesa. El segundo significado es más parecido a la maldición metafórica e imprecisa, por ejemplo, "Él murmuró un juramento cuando se golpeó el dedo con el martillo". De hecho, el Diccionario de la lengua española, en la segunda acepción de "juramento", define este vocablo como "voto o reniego" (RAE, 20I8).

\subsection{Lenguaje obsceno}

En un sentido metalingüístico, el uso del lenguaje obsceno generalmente equivale al uso de palabras malsonantes en general. Si bien el término "obsceno" señala que muchas de las palabras malsonantes se meten en temas y dominios que se consideran convenientes en el lenguaje personal, pero no en el social (esto es, funciones y deshechos corporales), en este contexto, entendemos el lenguaje desde un sentido metafórico. Esto es, aunque el lenguaje obsceno en contextos sociales puede equivaler a un abuso o una agresión, no siempre es así. Se puede utilizar el lenguaje obsceno sin tener que abusar de nadie ("Mierda, se me ha olvidado el informe") o como indicación de que se está relajado y cómodo ("Qué bien, salir de la oficina y poder relajarme, coño"). El uso correcto del lenguaje obsceno es complicado ya que las distintas funciones del lenguaje obsceno se abastecen del mismo suministro limitado de palabras.

\subsection{Maldiciones}

Al maldecir, se suele invocar a seres superiores o demonios para lograr un objetivo específico (por ejemplo: “Ojalá te pudras en el infierno durante toda la eternidad"). Son varios aspectos los que nos permiten distinguir las maldiciones de otras categorías, como las palabrotas o los juramentos: las maldiciones invocan la ayuda de un ser superior, implican más ritual y son deliberadamente más articuladas, se orientan al futuro (con vistas a un entendimiento de que el efecto puede retrasarse) y puede que no usen necesariamente lenguaje explícitamente soez. Las referencias a series superiores han supuesto que tradicionalmente las maldiciones no fueran aprobadas ni por la iglesia ni por la sociedad en general, pues en tiempos más religiosos las maldiciones se decían en serio y su intención era literal. Con los avances de la sociedad y sus creencias, las referencias explícitas a las deidades a menudo desaparecen y se pueden expresar maldiciones sin intervención divina específica (“¡Ojalá te mueras!”) y suelen ser más metafóricas (“¡Púdrete en el infierno!"), de modo que en ocasiones pueden estar directamente relacionadas con otras categorías o complementarse con ellas. 


\subsection{Obscenidades}

A diferencia de lo señalado en la categoría "lenguaje obsceno", consideramos la obscenidad el uso explícito de palabras indecentes o tabú para referirnos a partes íntimas del cuerpo y sus funciones o deshechos de manera literal (por ejemplo, "Iba andando y pisó una mierda").

\subsection{Palabras tabú}

La etimología de la palabra tabú permite claramente su definición, puesto que en polinesio significa "lo prohibido" (RAE, 2018). Así, las palabras tabú son aquellas palabras que, en una cultura dada, se han impuesto como prohibidas. Principalmente, suelen ser palabras irrespetuosas con la religión o que hacen referencia pública a actos íntimos, si bien también pueden incluir temas estigmatizados como las enfermedades mentales o los defectos de nacimiento. En determinados contextos, temas como la muerte, los ingresos o las tendencias políticas de una persona también suponen tabúes.

\subsection{Palabrotas}

Desde un punto de vista amplio, el Diccionario de la lengua española define las palabrotas como "Dicho ofensivo, indecente o grosero" (RAE, 2018). Por ello, son palabras $\circ$ frases malsonantes generalmente dichas en circunstancias emocionales. El significado literal superficial es secundario ("iHostia puta!", "No me jodas"), pues lo importante es la descarga de emoción. Las palabrotas suelen ser "prefabricadas" en el sentido de que son fijas e invariables (por ejemplo, "No me jodas" nunca se convertiría en "No te jodas"). Las palabrotas pueden ser reflexivas (es decir, pueden aludir al propio emisor: "Me cago en mi vida", "Qué gilipollas he sido"), pero también pueden dirigirse a otros ("Hijo de puta"), describir alguna situación en tono despectivo ("Este es un trabajo de mierda"), pueden incluir metáforas (“iVete a la mierda!”) o incluso denigrar con insultos (“Cabrón”).

\subsection{Vituperios}

Los vituperios son versiones "refinadas" o "sofisticadas" del insulto, que incluso puede utilizarse en determinados contextos formales (un buen ejemplo puede ser el Parlamento australiano, donde puede considerarse una forma de arte menor). Así, los vituperios pueden variar en su grado de sutileza, con mayor o menor ironía mordaz, ingenio o juegos de palabras, manteniéndose alejado de palabrotas $\circ$ uso de lenguaje obsceno convencionales. A menudo, permite al 
usuario insultar a su víctima sin utilizar palabras tabúes ni violando el protocolo social (por ejemplo, usar "gilipuertas" en lugar de "gilipollas").

\section{Conclusiones}

La principal dificultad que encontramos para desarrollar la conceptualización y la taxonomía de las categorías del lenguaje soez orientado a la traducción audiovisual es la diferencia cultural entre ambas lenguas de trabajo, inglés y español. Esta situación imposibilita emplear sin modificaciones en español la interesante propuesta de Wajnryb (2005). Por poner tan solo un ejemplo, la diferencia entre swear y oath de Wajnryb (2005), por ejemplo, no es fácil de marcar en español, ya que ambas podrían traducirse como "jurar" o "juramento"; vocablos que, por otro lado, no resultan demasiado naturales en español actual para hablar del tipo de expresiones aquí recogidas.

Como afirma Molina (2006), tanto la cultura como el lenguaje distorsionan la realidad y mediante la traducción se trata de reparar esa distorsión en el momento de trasvasar la realidad de una lengua y una cultura a otra lengua $y$ cultura diferentes. Sin embargo, consideramos que una clasificación de los tipos de lenguaje soez como esta es extremadamente útil como punto de partida para realizar una traducción y adaptación cultural de lo más precisa y adecuada de estos tipos de términos en los proyectos de traducción audiovisual.

Dentro de las diez categorías propuestas para la lengua española se pueden delimitar los distintos casos de lenguaje soez, de modo que facilitará la realización de una traducción lo más acotada posible, ya no solo al sentido literal del término en sí mismo, sino también a la intencionalidad que se pretende para tratar de conseguir un efecto similar en el público meta.

\section{Referencias bibliográficas}

Alcorisa, J. (2017). Estudio comparativo de la subtitulación del lenguaje ofensivo y tabú en Bojack Horseman. Trabajo de fin de grado. Universidad de Alicante. Recuperado de http://rua.ua.es/dspace/handle//0045/68828

Ávila-Cabrera, J, (2015). Propuesta de modelo de análisis del lenguaje ofensivo y tabú en la subtitulación. Verbeia: Journal of English and Spanish Studies = Revista de Estudios Filológicos, 8-27. Recuperado de https://eprints.ucm.es/50076/

Catalá, L. (2017). Análisis descriptivo de la traducción del lenguaje soez en el doblaje de Pulp Fiction. Trabajo de fin de postgrado. Universitat Oberta de Catalunya. Recuperado http://openaccess.uoc.edu/webapps/o2/handle/10609/65486 
Chaume, F. (2004). Cine y traducción. Madrid: Cátedra.

Fuentes-Luque, A. (20I4). El lenguaje tabú en la traducción audiovisual: Límites linguïsticos, culturales y sociales. CVC E-AESLA, Revista Digital de Lingüística Aplicada Recuperado de http://cvc.cervantes.es/lengua/eaesla/pdf/0I/70.pdf.

Molina, L., (2006). El otoño del pingüino: análisis descriptivo de la traducción de los culturemas. Castellón de la Plana: Publicacions de la Universitat Jaumel. Recuperado de https://books.google.es/books?id=GUIILs$36 \mathrm{CgC} \& \mathrm{lpg}=\mathrm{PPI} \& \mathrm{hl}=\mathrm{es} \& \mathrm{pg}=\mathrm{PA} 4 \# \mathrm{v}=$ onepage $\& \mathrm{q} \& \mathrm{f}=\mathrm{false}$

RAE. (20I8). Diccionario de la lengua española. Recuperado de http://dle.rae.es/.

Scandura, G. (2004). Sex, Lies and TV: Censorship and Subtitling. Meta, 49(I), I25I34. Recuperado de https://www.erudit.org/en/journals/meta/2004-v49-n I meta733/009028arl

Soler, B., (20I4). Traducción y doblaje: análisis de fuck y su traducción al español en Jackie Brown. Entreculturas: revista de traducción y comunicación intercultural, 6, 127-139. Recuperado de https://dialnet.unirioja.es/servlet/articulo?codigo $=4628675$

Wajnryb, R., (2005). Expletive deleted: a good look at bad language. Nueva York. Free Press. 